\title{
Nutrition, obesity and hormones
}

\author{
Marco Giammanco, ${ }^{1,2}$ Laura Lantieri, ${ }^{1,2}$ Gaetano Leto, ${ }^{3}$ Fulvio Plescia, ${ }^{1}$ Danila Di Majo ${ }^{1}$ \\ ${ }^{1}$ Department of Experimental Biomedicine and Clinical Neurosciences, University of Palermo; ${ }^{2}$ Research Unit in \\ Endocrinology, Italian Society of Experimental Biology; ${ }^{3}$ Department of Sciences for Health Promotion and \\ Mother-Child Care, University of Palermo, Italy
}

\begin{abstract}
Obesity is a chronic pathological condition with a multifactorial aetiology, characterised by an excessive body fat accumulation with multiple organ-specific consequences. Emerging evidence highlights that obesity appears to be associated with multiple alterations in the endocrine system. However, the mechanisms underlying the interactions between obesity and this system remain still controversial. This review discusses the impact of obesity on various endocrine systems and, in particular, would provide a general overview on the biochemical changes that may occur in each of these axes in association with obesity.
\end{abstract}

\section{Introduction}

Obesity is a chronic pathological condition with a multifactorial aetiology which comprises genetics, environment, metabolism, lifestyle, and behavioral components. ${ }^{1-3}$ Complex interac-

\footnotetext{
Correspondence: Marco Giammanco, Department of Experimental Biomedicine and Clinical Neurosciences, University of Palermo, Corso Tukory 129, Palermo, Italy.

E-mail: marco.giammanco@unipa.it
}

Key words: Obesity; Growth hormone; Thyroid hormones; Endocrine system; Nutrition.

Contributions: LL, MG preformed the literature search; LL, MG, GL, FP, DD wrote the manuscript draft. GL edited the translation.

Conflict of interest: the authors declare no potential conflict of interest.

Funding: the present research was supported with funds from the University of Palermo.

Received for publication: 8 August 2018.

Accepted for publication: 27 October 2018.

(C) Copyright M. Giammanco et al., 2018

Licensee PAGEPress, Italy

Journal of Biological Research 2018; 91:7755

doi:10.4081/jbr.2018.7755

This article is distributed under the terms of the Creative Commons Attribution Noncommercial License (by-nc 4.0) which permits any noncommercial use, distribution, and reproduction in any medium, provided the original author(s) and source are credited. tions between genetic and environmental factors which give rise to alterations of the endocrine and metabolic functions have been suggested to contribute to the pathogenesis of this disease. ${ }^{3}$ As these alterations are secondary, they may be often reversible following body weight loss. Therefore, these effects should be distinguished from those primary endocrine-metabolic disorders that, although uncommon, may foster the development of obesity. On the other hand, informations about those complications affecting the endocrine organs which occur in obese patients as a result of the accumulation of dysfunctional adipocytes also in ectopic sites, such as omental fat, pericardial and peri-renal fat are actually scanty ${ }^{4}$. However they can act as amplifiers of metabolic effects thus worsening the cardiometabolic risk factors in these subjects. ${ }^{4}$

\section{Growth hormone metabolism and obesity}

Recent evidence indicates that a functional decreased secretion of somatotropin or growth hormone $(\mathrm{GH})$ in obese subjects appears to be due to specific central mechanisms, ${ }^{5,6}$ such as an increase of the somatostatinergic tone, and/or to peripheral mechanisms such as increased circulating levels of insulin and free fatty acids (FFA). ${ }^{7}$ Furthermore, the reduction of the lipolytic and anabolic effects on muscles exerted by GH and its peripheral mediator, namely the insulin-like growth factor-1 (IGF-1), may further influence the accumulation of visceral fat and may also account for the related metabolic consequences. GH is a protein of 191 amino acids whose secretion from the pituitary is regulated by the hypothalamus. The neuroendocrine control of GH secretion is under the regulation of two neuropeptides, namely GH releasing hormone (GHRH) which stimulates GH secretion, and somatostatin (SS) which inhibits GH secretion. These molecules are produced in the neurons of the arcuate nucleus and ventromedial nucleus of the hypothalamus and in those of anterior periventricular nucleus respectively. GHRH and SS secretion are, in turn, regulated by central neurotransmitters, such as dopamine adrenaline, noradrenaline, serotonin, histamine and gamma aminobutyric acid. ${ }^{8}$ Furthermore, following the recent findings reshowing a stimulatory effect of the cholinergic system on GH secretion through the inhibition of the somatostatinergic tone, numerous studies have been directed to better clarify the role of this system on GH secretion. ${ }^{9}$ Furthermore, it is know that neuropeptides such as thyrotropin-releasing hormone (TRH), substance $\mathrm{P}$ and galanin contribute to modulate $\mathrm{GH}$ secretion via paracrine mechanisms. ${ }^{10}$ Moreover other hormones, such as leptin and ghrelin, have been recently proven to exert stimulatory effects on the release of GH. ${ }^{9}$ On the other hand the pituitary secretion of this hormone is pulsatile and follows a circadian rhythm with a peak concentration reached 1 hour after the onset of the sleep GH expression levels 
are up regulated by metabolic factors such as low blood sugar, amino acids, exercise and stress, while they are down-regulated by hyperglycemia, and increased circulating FFA. ${ }^{10,11}$ Other hormones, such glucocorticoids, thyroid hormones and gonadal hormones may act as GH regulators. ${ }^{12,13}$ Ultimately, the main effect of $\mathrm{GH}$ consists in stimulating mainly the hepatic synthesis and secretion of IGF-1, which mediates, in part, the metabolic effects of the pituitary hormone. The serum concentration of IGF-1, in turn exert a negative feedback on the secretion of GH. ${ }^{14,15}$

GH exerts a lipolytic effects mainly on the visceral adipose tissue and, to a lesser extent, on the subcutaneous adipose tissue. These effects result in an increase of the circulating levels of FFA. ${ }^{16}$ The effect of GH on adipose tissue consists in a reduction of glucose uptake and in an increased lipolysis. Unlike in adipose tissue, in the liver GH promotes the absorption of triglycerides by increasing the expression of lipoprotein lipase (LPL) and that of hepatic lipase. ${ }^{17} \mathrm{GH}$ directly stimulates the uptake of amino acids into muscle cells, thus increasing protein synthesis and, consequently, muscle growth. ${ }^{17}$

GH plays a pivotal role in the regulation of the intermediary metabolism, body composition and energy expenditure (on the other hand, the hyperglycaemic, lipolytic and anabolic effects of this hormone are well know). Overall, GH acts by directing energy metabolism preferentially toward lipids oxidation, then towards glucose oxidation and finally to protein oxidation. This sequence of events ultimately provides the energy derived from the food needed for protein synthesis. GH also affects the body composition via its anabolic, lipolytic, sodium retaining effects and promotes bone mineralization. Among the different metabolic effects induced by GH, those exerted on lipid metabolism were the first to be recognized. The stimulation of lipolysis in adipose tissue leads to an increase of the circulating FFA. The presence of GH receptors on preadipocytes and adipocytes is of crucial importance for the lipolytic effect of GH mediated by LPL and by hormone-sensitive lipase (HSL), respectively. LPL is the enzyme responsible for the hydrolysis of the triglycerides contained in VLDL and chylomicrons and which is involved in the production of circulating in FFA which, in turn, are internalized and stored in the adipocytes. GH negatively regulates LPL by inhibiting the enzyme activity rather than the transcription of the gene encoding for GH. In this way GH decreases the adipose accumulation mainly at the abdominal compartment level. It is worth noting that the facilitating effects of $\mathrm{GH}$ on the proliferation and differentiation of preadipocytes may be also exerted through the paracrine/autocrine activity of Insulin Growth Factor-I (IGF-I) produced by the adipose tissue. Other enzyme involved in the regulation of adipogenesis such as HSL, promotes the normal lipolysis through the intracellular hydrolysis of triglycerides into glycerol and FFA. FFA are the energetic substrate needed for those tissues with a high metabolic rate, first of all skeletal muscle. The effects of GH on carbohydrate $(\mathrm{CHO})$ metabolism are more complex. These effects may be indirectly regulated by antagonizing those induced by insulin. The final effect is the reduction in the metabolism of $\mathrm{CHO}$ to the detriment of lipids. The effects of GH on protein metabolism are also well known. Its anabolic activity on protein synthesis is the consequence of the stimulation of amino acid uptake by tissues and their incorporation in the proteins. The lipolytic and anabolic properties of GH may account for the role of this hormone in the regulation of body composition, its facilitating effects on the development of muscular component or its inhibiting effects on fat accumulation. Finally, the close relationship between nutrition and somatotropic secretion is evident during the fasting and the postprandial period. In fact during fasting, and/or physical stress, GH secretion is amplified, while the excess of nutrients, such as glucose and FFA, inhibits the release of GH. ${ }^{18-26}$ Specific amino acids, in particular lysine and arginine (Arg), may also stimulate $\mathrm{GH}$ secretion. ${ }^{27}$ This phenomenon is a clear proof about the correlation between $\mathrm{GH}$ and amino acid metabolism whose aim is to act as anabolic hormone (thus boosting protein synthesis), in presence of an excess of amino acids. However, GH plays a marginal role during the postprandial phase, while high levels of insulin inhibit protein catabolism and lipolysis. The significant relationship between GH and protein metabolism is confirmed by the fact that GH deficiency results in a net loss of lean body mass. These findings strongly support the hypothesis of close relationship between nutritional status and somatotropic secretion.

Some nutritional factors function as regulators of the serum levels of Insulin-like growth factor-1 (IGF-1). ${ }^{28}$ For instance, malnutrition and protein deficiency, are associated with a low level of this hormone. In man a fasting condition induces a marked decrease of IGF-1 circulating levels which after 10 days results in a $15-20 \%$ reduction as compared with baseline values. However, IGF-1 levels return to normal values following re-feeding. ${ }^{29}$ These findings suggest that some nutritional factors may be involve in particular, in the modulation of IGF-1 secretion during malnutrition due to protein deficit nutrition. ${ }^{30,31}$ Several studies have shown that many protein foods are positively correlated with the IGF-1 levels, in particular: meat, fish, cheese, tofu, beans, lentils, yogurt, eggs, nuts, and seeds. ${ }^{32,33}$ In addition to protein foods, carbohydrate and lipids appear to have also a role in the modulation of IGF-1 secretion. ${ }^{34}$

Until a few years ago, GH was thought to act mainly on children growth rather than to exert metabolic effects. However, growing evidence in these recent years has highlighted that GH plays a key role not only in puberty, but also in adulthood. For instance $\mathrm{GH}$ has been proven to be involved in a pathological condition which is well known as GH deficiency syndrome (GHD). This condition is characterized by metabolic, functional and structural changes such as increase of visceral fat, decrease of lean mass, osteopenia and/or osteoporosis, alterations in lipid and carbohydrate metabolism, decrease of muscle strength and exercise tolerance, increased mortality due cardiac and cerebrovascular accidents, reduced psyco-physical wellness and therefore reduced quality of life rating. ${ }^{35,36}$ Short term studies have shown that the biological alterations associated with GHD may be reversible upon treatment with recombinant $\mathrm{GH}$ (rhGH). ${ }^{37-40}$ Current guidelines for the diagnosis of GHD in adults are primarily based on the indications of the GH Research Society (GHRS), which indicate that the diagnosis of GHD, must be demonstrated by the stimulation tests of GH secretion. ${ }^{41}$ The new recommendations, published in $2011,{ }^{41}$ suggest to submit to the test for GHD to the following patients: i) Subjects with signs and symptoms of hypothalamicpituitary disease of endocrine, structural and/ or genetic origin; ii) Subjects who underwent cranial irradiation or clinical treatment for brain tumors; iii) Subjects with traumatic brain injury or subarachnoid hemorrhage. ${ }^{41}$

In order to diagnose GHD in adult patients, only one stimulation test is needed. The measurement of basal levels of IGF-1, as well as that of other markers, has not been considered appropriate to distinguish between subjects with normal GH levels and GHD subjects. Although normal levels of IGF-1 does not rule out a severe GHD, very low levels are highly suspicious for GHD. Therefore, it is currently suggested that in the absence of other catabolic conditions, and/or liver disease, very low levels of IGF1 may be considered diagnostic for the presence of severe GHD. Moreover, the deficiency of three additional pituitary hormones is 
considered highly predictive for GHD. ${ }^{42}$ However, the insulin tolerance test (ITT) is considered the gold standard for diagnosis of GHD. The degree of severity of GHD is defined in presence of GH levels $<3 \mu \mathrm{g} / \mathrm{L}$. On the other hand, Aimaretti et al. ${ }^{43}$ have shown that $\mathrm{GH}$ values comprised between 3 and $5 \mu \mathrm{g} / \mathrm{L}$ following stimulation with ITT represent the first and the third centile of the results of the test in lean subjects. However, this test is contraindicated in certain types of patients, such as those showing evidence of electrocardiographic abnormalities or with ischemic heart disease, epilepsy or brain damage, or in elderly patients. ${ }^{44}$ In patients where the ITT test is contraindicated, other stimulation tests should be used. To date, the GHRH + Arg test is the most widely used in patients with suspected GHD of pituitary origin. This type of test is usually well tolerated and does not cause serious side effects such ITT induced hypoglycaemia. If the values of Body Mass Index (BMI) are taken as cut-off limit, then severe GHD is defined in presence of GH levels $<11.5 \mu \mathrm{g} / \mathrm{L}$ in lean subjects $(\mathrm{BMI}<25$ $\left.\mathrm{kg} / \mathrm{m}^{2}\right) ;<8 \mu \mathrm{g} / \mathrm{L}$ in overweight subjects (BMI $25-30 \mathrm{~kg} / \mathrm{m}^{2}$ ) and $<4.2 \mu \mathrm{g} / \mathrm{L}$ in obese subjects (BMI $\left.>30 \mathrm{~kg} / \mathrm{m}^{2}\right) .{ }^{45}$ The response to $\mathrm{GHRH}+$ Arg negatively correlates with age, and BMI. ${ }^{46-48}$

The goal of the replacement therapy with GH is the correction of structural functional and metabolic abnormalities which are a characteristic of GHD. According to the GHRS guidelines the starting daily dose of GH to be administered should be $0.2-0.3 \mathrm{mg} /$ day in man and woman respectively, and $0.1 \mathrm{mg}$ /day in older patients independent of patient body weight. ${ }^{49}$ In fact, this parameter is not recommended for adjusting the dose as this molecule undergoes wide inter-individual variation of absorption and response. Another reason is that the administration of increased level of doses in patients with higher weight is not in use. Recently it has been shown that the response to $\mathrm{GH}$ treatment may vary according to the gender. ${ }^{50} \mathrm{In}$ fact men appear to be more responsive than women to $\mathrm{GH}$ treatment. This phenomenon results in an improving of body composition, lipid metabolism and bone mass. ${ }^{50}$ In order to monitor appropriately the clinical response to $\mathrm{GH}$, a baseline assessment of body composition, bone mineral density, lipid and glucose metabolism and psycophysical conditions are required. ${ }^{51}$

\section{Body composition in adults with growth hormone deficiency syndrome}

Adult patients with GH deficiency syndrome (GHD) show modifications of body composition. ${ }^{35,36}$ These patients have an increased fat mass (FM), with a characteristic distribution of fat in the abdomen, and a reduction of lean body mass (FFM). ${ }^{37,38}$ In addition, these patients show a reduction in total body water as compared to normal subjects. ${ }^{37-40}$ These alterations are present to a greater extent in patients whose hormone deficiency occurred during childhood than in patients whose deficiency occurred in adulthood. ${ }^{52}$ Furthermore, it has been reported that alterations in body composition are related to the severity of the GHD. ${ }^{53}$ Numerous studies have shown mainly a significant reduction of visceral FM and, to a lesser extend an increase of FFM in response to therapy with rhGH. ${ }^{54-56}$ Likewise as observed for muscle mass, several studies have shown after treatment with rhGH an increase in isometric strength and isokinetic contraction, accompanied by an increase physical exsercise performed. ${ }^{57,58}$

GH has been shown to stimulate not only the longitudinal bone growth during childhood and adolescence but also regulates bone turnover throughout the lifetime. ${ }^{59}$ Clinical evidence shows that adult patients with GHD have a significant reduction in bone mineral density, which mainly involves the trabecular bone and are at high risk of osteoporotic fractures of vertebral column. ${ }^{60}$ According to recent studies, the replacement therapy with rhGH induces important effects on bone metabolism. ${ }^{60}$ However these effects appears to be less marked in patients with adulthood $\mathrm{GH}$ than in patients with pediatric GH deficiency. ${ }^{55}$ This difference may be likely due to the attainment of a normal peak bone mass in patients who acquire the deficit in the ederly. ${ }^{61}$

Numerous epidemiological studies have demonstrated that adult hypopituitary patients with GHD undergoing replacement therapy for deficits of all pituitary hormones but not for GHD, had a shortened life expectancy and a twofold increased risk of cardiovascular and cerebrovascular diseases as compared to controls. ${ }^{62}$ Although many other factors may contribute to increase this risk, it was suggested that GHD might play a predominant role. In addition to the structural and functional alterations of cardiac muscle, the increased mortality from cardiovascular events in patients with GHD appears to be the result of changes in body composition, lipid metabolism, blood pressure, insulin resistance and presence of chronic inflammatory conditions. ${ }^{62,63}$

Adult patients with untreated GHD show a significant reduction in quality of life $(Q o L)$ in terms of reduction of vitality, tendency to social solitude and emotional alterations. These conditions may improve following a replacement therapy with GH. The positive effects of this therapy are due to an improvement in cognitive functions such as memory and concentration, mood, psychological well-being and physical strength. In particular, patients with juvenile-onset GHD $Q o L$ appear to be less influenced. ${ }^{51}$

\section{Thyroid hormones nutrition and obesity}

The pulsatile secretion and the circadian rhythms of thyroid hormones are stimulated by thyrotropin (TSH) produced by thyrotrophic cells of the anterior pituitary. TSH secretion, in turn, is stimulated by TRH. ${ }^{64}$ The secretion of TSH is also inhibited by very small increases of thyroid hormones concentrations and in response to small decreases of triiodothyronine $\left(\mathrm{T}_{3}\right)$ and thyroxine $\left(\mathrm{T}_{4}\right)$. The physiological role of TRH is that to regulate thyroid hormone induced TSH secretion. Other mechanisms that mediate this effect are a decrease in the TRH secretion from the hypothalamus and a decrease of the number of TRH receptors on pituitary cells respectively. Furthermore, TRH activity can be inhibited by somatostatin, dopamine and elevated concentrations of glucocorticoids. ${ }^{64}$ In conclusion, the thyroid axis represents a classic example of feedback loop of endocrine system: hypothalamic TRH stimulates the pituitary TSH production which, in turn, stimulates the synthesis and secretion of thyroid hormone. Thyroid hormones, inhibit the production of TRH and TSH by a negative feedback mechanism. ${ }^{65}$ The homeostatic set point of hypothalamus pituitary thyroid (HPT) Axis is determined by TSH.

Deiodinase (5'-iodothyronine deiodinase), is an enzymes that convert $T_{4}$ to $T_{3}$. Deiodination is the main metabolic pathway of thyroid hormone. ${ }^{66}$ The daily production of $\mathrm{T}_{3}$ account for the $20 \%$ of its total production, while the remaining $80 \%$ results from deiodination in peripheral tissues. The process of deiodination is mediated by a series of three types of enzymes i.e., the iodothyronine deiodinase (ID). ${ }^{67}$

Deiodinase I (ID-I), is important for the production of $\mathrm{T}_{3}$ from $\mathrm{T}_{4}$ in peripheral tissues. The enzyme is present in the kidney, in the endoplasmic reticulum of the liver cells and in the plasma membrane of renal and thyroid cells. ${ }^{68}$ Deiodinase II (ID-II). 
This enzyme is present in the brain, pituitary, brown adipose tissue and placenta. In humans, ID-II is also expressed in the thyroid gland, heart, and skeletal muscle. ID-II is endowed with deiodinase activity located in the outer ring. Therefore it is important for the intracellular production of $\mathrm{T} 3$ in these tissues. It also keeps constant $\mathrm{T}_{3}$ levels in the central nervous system. ${ }^{68}$ Deiodinase III (IDIII) is present in the brain, skin, placenta and in some foetal tissues. It it endowed with deiodinase activity located only the inner ring and therefore allows the production of reverse $\mathrm{T}_{3}\left(\mathrm{rT}_{3}\right)$, an inactive form of $\mathrm{T}_{3}$, from $\mathrm{T}_{4}{ }^{69}$

An increasing number of studies in these recent years has been carried out in order to investigate the possible relationship between body weight and thyroid function. It is well known that hyperthyroidism leads to weight loss while hypothyroidism is associated with weight gain and a generalized distribution of adipose tissue. However, the changes of the thyroid function in obesity are still controversial. In fact, obesity, and in particular the android phenotype, is associated with multiple endocrine abnormalities such as insulin resistance, gonadal dysfunction, alterations of both pituitary adrenal and somatotropic axis..$^{70}$ On the other hand, the relationship between obesity and thyroid dysfunction are still not well understood. ${ }^{71}$ Obese subjects present alterations of the thyroid functions, in particular, an increase of TSH (in the absence of thyreopaties), and that of $\mathrm{T}_{3}$, i.e., the metabolically active form of the hormone. ${ }^{72,73}$ Conversely, no changes are observed in total and free $\mathrm{T}_{4}$, whose levels are similar in obese and normal weight. In addition, fasting and overeating do not influence the concentrations of serum $\mathrm{T}_{4}$. This phenomenon demonstrates the lack of relationship between circulating $\mathrm{T}_{4}$ and body weight. ${ }^{74}$ Alterations in the negative feedback of HPT axis, occur in obese subject. These effects result in an increase of T3 that is not followed by a reductions of TSH. It is well known that in obese subjects TSH and body mass index (BMI) are positively correlated. ${ }^{75}$ In fact, many studies undertaken in children, adolescents, and adults have shown that TSH levels increased slightly in the obese subjects, compared to normal weight subjects. In a cross-sectional study, Knudsen et al., ${ }^{76}$ showed that, in addition to the positive correlation between BMI and serum TSH, an increase in BMI is associated with an increase in serum TSH levels within 5 years. These data were confirmed by another longitudinal study of Svare et al. ${ }^{77}$ High levels of TSH in obesity may be due to a neuroendocrine dysfunction that causes an abnormal secretion. In particular leptin, a hormone produced by adipocytes, has been shown to alter the HPA axis. ${ }^{78}$ In humans, leptin and TSH undergo a very similar circadian rhythm. Leptin deficiency is closely associated with the deregulation of pulsatile patterns and circadian rhythm of TSH secretion. ${ }^{79}$ These findings suggest a possible role of leptin in the regulation of TSH with resetting the thyroid axis. ${ }^{80,81}$ On the other hand the production of TSH is also regulated by neurotransmitters and hormones repletion as neuropeptide $\mathrm{Y}, \alpha$-melanocyte-stimulating hormone, and agouti-related peptide (AgRP) that regulate body weight and activate the hypophysiotropic thyrotropin-releasing hormone (TRH) neurons. These transmitters are influenced by leptin, which at peripheral level, modulates, also mono-deiodinase in different tissues, depending on the energy status. These results suggest that TSH levels may be considered as marker of alteration of the energy balance in obesity. In addition, the increased TSH levels may indicate the presence of a hormone-resistance status. Despite the increased levels of TSH, $\mathrm{T}_{3}$ remains elevated too. This effect seems to be due to a decreased expression of TSH receptors in peripheral tissues which, in turn, leads to a down-regulation of thyroid hormone receptors and consequently to an increase of TSH and free $\mathrm{T}_{3}$ $\left(\mathrm{fT}_{3}\right)$ levels. ${ }^{82,83}$ Total and free $\mathrm{T}_{4}\left(\mathrm{fT}_{4}\right)$ levels do not undergo evident changes in obese subject, while a moderate increase in TSH is associated with a slight increase in $\mathrm{fT}_{3}$, total $\mathrm{T}_{3}$ and thyroid volume respectively. ${ }^{84}$ The slight increase of $\mathrm{fT}_{3}$ levels in obese subjects could be interpreted as compensation mechanism following to an excessive accumulation of fat mass and an increased type II deiodinase activity that converts $T_{4}$ to $T_{3}$, in order to increase the energetic expenditure. ${ }^{85}$ In this context, a positive association between $\mathrm{fT}_{3} / \mathrm{fT}_{4}$ ratio (i.e., the deiodination index), waist circumference and BMI, ${ }^{86}$ has been highlighted in obese patients. These data suggest that, due to the increased deiodinase activity, a high rate of conversion from $\mathrm{T}_{4}$ to $\mathrm{T}_{3}$ may occur, as a compensatory mechanism to the increase of adipose tissue. These effects lead to an increase in the rate of basal metabolism and, consequently, to an improvement in energy expenditure. Ultimately, TSH and $\mathrm{fT}_{3} \mathrm{lev}$ els are elevated in obese patients. Assuming that the inappropriate increase of TSH is caused by a reduced inhibitory effect of leptin, then the increase of $\mathrm{fT}_{3}$ should be considered an adaptative mechanism to the changes in mono-deionization, that decrease to the rate of energetic source available for conversion into fat. ${ }^{87}$ In line with this hypothesis, the high levels of TSH in obese subjects tend to normal value following a substantial weight loss. In addition, thyroxine based therapy in obese patients with moderately elevated levels of TSH does not affect body weight or lipid profile. Clinical observations have highlighted that in the obese patients on diet, the treatment with $T_{3}$ and $T_{4}$, even at physiological doses, induces a subclinical hyperthyroidism. Therefore, this therapy should be discouraged in obese, euthyroid patients. These findings question the diagnosis of subclinical hypothyroidism in obesity and indicate that a slight increase in TSH levels is a consequence rather than a cause of obesity. Furthermore, as mentioned previously, thyroid hormones, in particular triiodothyronine or $\mathrm{T}_{3}$, should be used in the long term treatments of obesity due their ability to increase energy expenditure. However, due to the onset of thyrotoxic side effects, i.e., increased heart rate, cardiac hypertrophy, decreased lean body mass, alteration of hypothalamus-pituitary-thyroid axis, the clinical use of $\mathrm{T}_{3}$ as an anti-obesity drug has been abolished. Recently, it has been shown that the 3,5-diiodo-1-thyronine $\left(\mathrm{T}_{2}\right)$, a naturally occurring iodothyronine produced by the thyroid, is endowed with biological activities similar to those of $\mathrm{T}_{3}$ but is devoid of tireotoxic effects. ${ }^{88}$ Recent experimental in vivo studies have shown that the administration of $T_{2}$ in rats fed diets rich in lipids induces a decrease of circulating cholesterol and triglycerides and a reduction of body weight without inducing hepatic steatosis. ${ }^{89}$ These data demonstrate that multiple treatments with high doses of $\mathrm{T}_{2}$ inhibits the secretion of TSH and prevents the onset of hepatic steatosis in rats fed diets rich in lipids. ${ }^{89}$

Increasing evidence indicates the presence of possible interactions between nutrition and endocrine system. Food exerts marked short term and the long term effects on the production of hormones and their blood levels. At the same time, many physiological effects of foods are regulated by hormones. ${ }^{90}$ Thyroid function also is susceptible to acute and chronic alterations induced by quality and quantity of ingested nutrients. Thyroid hormones exert important functions aimed at maintaining energy homeostasis. In fact thyroid gland plays a central role in the regulation of energy metabolism, thermogenesis, glucose and lipid metabolism. Additionally, thyroid gland is also involved in the regulation of food intake. ${ }^{91}$ The effects of thyroid hormones on glucose metabolism influence several biological functions. In fact $\mathrm{fT}_{3}$ increases the rate of gastrointestinal absorption of carbohydrate, and modulate glicolysis, gluconeogenesis and insulin secretion. ${ }^{91}$

On the other hand, carbohydrate play an important role on the metabolism of thyroid hormones. ${ }^{92}$ 
In this context although $\mathrm{T}_{4}$, represent the main hormone secreted by thyroid gland, it is only a pro-hormone that need to be converted to $\mathrm{T}_{3}$ in the pheripheral tissues, through a deiodination reaction involving the outer rings of $\mathrm{T}_{4} \cdot{ }^{93}$ Numerous studies have shown that carbohydrate are able to significantly modulate the reactions of deiodination of $\mathrm{T}_{4}$ to $\mathrm{T}_{3}$. For instance, in humans, serum $\mathrm{T}_{3}$ levels are directly correlated to the rate of CHO intake. ${ }^{94}$ This results in an increase of the thyroxine 5'-monodesiodase activity in the brown adipose tissue and in the liver. However no significant changes in serum levels of thyroid hormones occur. ${ }^{95}$ Several studies have also revealed that, in humans the rate of synthesis of $T_{3}$ from $T_{4}$ that decreases during fasting and returns to normal levels during re-feeding. ${ }^{96}$ In particular, the re-feeding with $\mathrm{CHO}$, is able to revert the changes occurred in serum levels of $\mathrm{T}_{4}$, $\mathrm{T}_{3}, \mathrm{rT}_{3} .{ }^{97}$ Finally thyroid hormones have many effects on the regulation of lipids synthesis, absorption and metabolism. ${ }^{98}$ These molecules act on 3-hydroxy-3-methylglutaryl coenzyme A reductase, which is the key enzyme in the biosynthetic pathway of cholesterol. ${ }^{98}$ In addition, several studies have shown that serum lipids are associated with TSH levels. ${ }^{99,100}$ On the other hand, the increased consumption of dietary fats in Western-type diets, which is one of the main factors responsible for the increase in body weight, has been correlated with specific alterations of thyroid axis functions. ${ }^{101}$ Furthermore, it has been observed that the dietary intake of oxidized lipids may induce an increase in the plasma levels of total $\mathrm{T}_{4}$, in part by interfering with the circulating levels of selenium, a component of the deiodinase type I enzyme whose role in the metabolism of thyroid hormones is well known. ${ }^{102}$ Finally, it is well established that TSH levels are correlated with circulating lipids. ${ }^{103}$ Early evidence have indicated that oxidized fats may increase $\mathrm{T}_{4}$ levels. ${ }^{104}$

\section{Diet, obesity and hormones}

Several studies have shown that the adoption of a Mediterranean diet (MD), provides protective effects against most of the widespread chronic diseases. ${ }^{105}$ In these studies, the concept of MD has been translated into a diet characterized by: i) a high consumption of vegetables, legumes, fruits and nuts, olive oil and cereals (which in the past were mainly wholemeal); ii) a moderate consumption of fish and dairy products (especially cheese and yogurt) and red wine during meals; iii) by a low consumption of red meat, white meat and saturated fatty acids. ${ }^{106}$ In line with these observation studies of Esposito et al. ${ }^{107}$ have reported that in adults the strict adherence to MD resulted in the prevention of hypertension, hypercholesterolemia, diabetes and obesity. On the other hand meta-analysis studies conducted by Sofi et al. ${ }^{108}$ have shown how MD act as a protective factor against all causes of mortality, in particular those related to cardiovascular disease or cancer, and also to Parkinson's disease and Alzheimer's disease. In a recent study carried out on Spanish and Italian subjects, Baldini showed how the younger generations seem to gradually and steadily leave $\mathrm{MD}$, in favor of new food trends which are characterized mainly by foods high in fat. ${ }^{109}$ The benefits of MD on healthy status are well documented. ${ }^{110}$ There is convincing evidence that the adherence to the traditional MD was associated with an increase in lifespan, ${ }^{111}$ a reduction in global mortality, lower incidence of coronary heart disease and atherosclerosis, metabolic syndrome (MetS) and the biochemical markers of Insuline resistance (IR), inflammation or risk of cardiovascolare diseases. ${ }^{112}$ However, few prospective studies have investigated the association between adherence to the
MD and risk of obesity. ${ }^{113,114}$ There are several physiological effects that may explain why the key components of MD may protect subjects from increase of body weight thus preventing the onset of obesity. MD is rich in plant-based foods that provide a large amount of dietary fibres which increases satiety and increases the secretion of Cholecystokinin. ${ }^{115}$ The MD foods have a low energy density, a low glycemic index and a high water content. These characteristics provide a full satiety and a lower calories intake, thus fostering the prevention of weight gain. MD contains high levels of mono-unsaturated fat, which provide about $67 \%$ of energy from fat, and low levels of saturated and trans-unsaturated fats. This pattern of fatty acids expression may provide important benefits on the health status. ${ }^{116,117}$ In fact, diets rich in monounsaturated fat, appear to improve glucose metabolism, and increase post-prandial fat oxidation as compared to diets rich in saturated fats. These phenomena may provide, in part, an explanation on why the consumption of olive oil is less likely to cause an increase of body weight.

The history of milk is as old as the history of the mankind itself. Since several millennia milk has been one of the staple of foodstuffs. Different types of milk such as sheep, goat, donkey in addition to breast milk can be used for human consumption in the first period of life. However, in general when talking about milk, this term refers to cow's milk. Milk is composed for $87 \%$ of water in which are dispersed protein of high biological value $(3.3 \%)$, fats, (mainly saturated short-chain fats) $(3.6 \%)$, easily digestible, sugars $(4.9 \%)$ mainly lactose, a disaccharide sugar composed of galactose and glucose. Vitamins which are present in large amounts in milk are, among the liposoluble vitamins, vitamin A and carotenes, and vitamin B1, B2, vit. B12 and pantothenic acid among the water-soluble vitamins. Among milk minerals, of particular importance for human nutrition is calcium, whose milk is the main source $(120 \mathrm{mg} / 100 \mathrm{~g})$, and which is present in a form that is easily absorbed by the body. ${ }^{118}$ Recent growing clinical evidence, suggests that the increased amount of calcium in the diet is associated with a preventive effect of some risk factor related to cardiovascular diseases such as hypertension,overweight, obesity, and metabolic syndrome. ${ }^{19-121}$ The NHANES study McCarron et al. carried out in the early 1980 s on 10,000 subjects aged $18-74$ years, highlighted an inverse association between high intake of calcium in the diet and body weight. ${ }^{122}$ These observations were confirmed by subsequent NHANES III studies of Zemel et al. ${ }^{123}$

These two studies have laid the groundwork to investigate the correlation between calcium intake (and milk) and body composition in humans. To date, numerous observational studies, mainly cross-sectional studies and retrospective studies have examined the relationship between rate of milk intake and body weight variation. ${ }^{124,125}$ Most of these studies have highlighted a statistically significant inverse association between these two parameters thus suggesting that low levels of milk intake is associated, either in children or in adults, with an increase of fat mass and an increased risk of developing overweight and obesity over the time. However, a few randomized controlled clinical investigations have examined the effect of a higher intake of milk on body weight. Other studies have shown an inverse association between dietary calcium levels in particular from dairy sources, and body weight in children and in adults. In particular, a study carried out by Barba et al. ${ }^{126}$ showed that milk consumption was significantly inversely associated with BMI (Z-score). This was the first study reporting a significant inverse association between rate of milk consumption and BMI in children. In 2006 a cross-sectional study by MarquesVidal et al. ${ }^{127}$ evaluated the relationship between milk consumption and body mass index in a Portuguese adult population. 
These investigations showed a significant negative correlation between higher consumption of milk and BMI. Finally, a randomized controlled clinical trial of Gilbert et al. ${ }^{128}$ carried out to assess the influence of milk supplementation on appetite markers in obese women undergoing weight loss concluded that milk supplementation attenuates the orexigenic effect, thus leading to more consistent weight loss.

There are currently several physiological mechanisms proposed to explain the anti-obesity effect of milk. ${ }^{128}$

There is evidence that in adipocytes, the intracellular calcium $\left(\left[\mathrm{Ca}^{2+}\right] \mathrm{i}\right)$ decrease the rate of lipogenesis. ${ }^{129}$ The intake of dietary calcium is inversely associated with $\left(\left[\mathrm{Ca}^{2+}\right] \mathrm{i}\right)$ levels. This phenomenon which has been observed to occur in vitro (on adipocyte cultures) and in vivo (in mice) is well known as the calcium paradox. ${ }^{129}$ The studies show that the amount of $\mathrm{Ca}^{2}+$ intake from the diet is inversely associated with the levels of $\left(\left[\mathrm{Ca}^{2}{ }^{+}\right] \mathrm{i}\right)$. Therefore, an increased calcium intake leads to a reduction of $\left(\left[\mathrm{Ca}^{2}+\right] \mathrm{i}\right)$, to an increased lipolysis and to a body weight loss. This paradoxic effect is explained by the equilibrium established between dietary calcium intake and calcium-regulating hormones dependent on [Ca2 +] I. ${ }^{130}$

Human studies have confirmed that calcium supplementation in the diet results in significant suppression of intact parathyroid hormone (iPTH) and calcitriol. These effects lead to a reduction of $\left[\mathrm{Ca}^{2+}\right]$ i resulting in increased lipolysis and body weight loss. ${ }^{131}$

Besides the calcium paradox, the anti-obesity effect of milk had been explained by the increase in fecal excretion of fats caused by calcium. ${ }^{132}$ The mechanisms by which calcium may increases fat excretion is probably the result of an interaction between calcium itself and saturated fatty acids, which cause the formation of insoluble fatty acid soaps thus leading to a lower fat absorption. ${ }^{132}$ The excretion of fecal fat induced by calcium has also been demonstrated to occur in humans. In fact several intervention studies, have shown that an increased dietary calcium intake induced steatorrhea. ${ }^{133,134}$ Other mechanisms have been proposed to explain the thwarting effects of milk on obesity and in particular: i) Calcium may cause a reduction in the cortisol production in adipocytes by inhibiting the expression of $11 \beta$-hydroxysteroid dehydrogenase, the enzyme that converts cortisone to cortisol, thus leading to a lower visceral fat accumulation; 135 ii) Increased expression of Mitochondrial uncoupling proteins 2 in white adipose tissue and consequently thermogenesis, ${ }^{136}$ iii) Nicotinamide riboside, a precursor of vitamin B3, present in milk, appears to play an important role in preventing obesity. It acts by improving antioxidant activities; ${ }^{137} \mathrm{iv}$ ) It has been reported that milk proteins can suppress the recruitment of short-term food, by regulating the hunger and satiety mechanisms. ${ }^{138}$

Several investigations have been directed to assess the influence of nutrition on the endocrine axis in obese subjects. The study evaluated the influence of nutrition on the endocrine axes by following two lines of investigational approaches: the first was based on the assessment of body composition in relation to the functional dysregulation of somatotropin axis while, the second one was focused on the influence of nutrition on the endocrine axes and the adherence to the MD. ${ }^{139}$ With regard to the first research line, endocrine changes associated with obesity and its phenotypic variability were evaluated in a cohort of subjects with moderate to severe obesity who were elegible for bariatric surgery. In line with previous observations from other studies GH deficiency has been found in almost half of the subjects. ${ }^{139}$ As expected, GHD subjects showed a higher prevalence of hypercholesterolemia and type 2 diabetes. Additionally these subjects also showed statistically significant differences in anthropometric and metabolic parameters. In addition, GHD subjects showed to have greater FM and FFM less than normal GH levels subjects. Instead, more than half of the subjects showed deficient levels of IGF-1, which were associated with a higher prevalence of hypercholesterolemia and MetS when peripheral mediators of GH effects were considered. In particular, individuals with deficits of IGF-1 showed no statistically significant differences in anthropometric, metabolic and hormonal parameters when compared to the group with sufficient levels of IGF-1 while, they showed an higher FM and a lower FFM. The association between low levels of IGF-1 and MetS was also confirmed by recent studies. ${ }^{140,141}$ Among the main anthropometric parameters considered, as a surrogate of central adiposity, circumference vitae, resulted the best predictor of GH secretion, which was not related to BMI. In agreement with other previous studies, this effect emphasizes the role of visceral fat in influencing the decrease of GH secretion. ${ }^{139}$ In particular, it has been shown that $1 \mathrm{~cm}$ increase in circumference vitae is associated with a decrease of GH peak of about $1 \mu \mathrm{g} / \mathrm{L} .{ }^{142}$ Thus, in line with previous studies, the results of the first line of research showed that the increased visceral adiposity contributes to the reduction of GH secretion. The deficiency of the secretory GH/IGF-1 axis due to the increase of visceral fat, can contribute in turn to determine a further accumulation of visceral fat, thus creating a sort of maladaptive circuit, which may result in an increased risk of cardiovascular diseases. These findings also shows that the assessment of body composition in obese, in terms of anthropometry and bioimpedentiometry, could be a useful initial screening to identify those subjects at higher risk of deficiency of GH secretion and for which the GHRH + Arg test could, likely, have a positive result.

The second line of research, was directed at evaluated the adherence to the MD and the influence of nutrition on the endocrine axes in subjects with moderate and severe obesity eligible for bariatric surgery in this case too.

By dividing the population into males and females, the percentiles for BMI, circumference vitae and age were calculated, from which it was observed that the subjects with the greatest adherence to the MD are those in the lowest percentile of BMI and circumference vitae, both for males and females, with circumference vitae as a major predictor of adherence to linear regression MD. In particular, it has been highlight that the free leptin index (FLI) positively correlated with foods typical of the MD (i.e., extra virgin olive oil, vegetables, legumes, fish, poultry and nuts) and the total caloric content, whereas no correlation was observed with the nutrients distribution. The MD is an example of diet endowed with anti-inflammatory and anti-oxidant effects. ${ }^{106}$ These effects could, in part, explain the correlation with the FLI. There are few epidemiological studies that have investigated the potential impact of a complete dietary pattern (namely, the diet, not individual foods), on the characteristics of non-alcoholic fatty liver disease (NAFLD) and its severity. Recently, a clinical intervention study of Ryan et al. ${ }^{143}$ showed that the MD improves insulin sensitivity and NAFLD as compared with a low fat content and high carbohydrate content. ${ }^{143}$ Although a greater adherence to the MD was not associated with a lower risk to develop NAFLD, the subjects with a strict adherence to this model appear to have a beneficial effect on the severity of the disease as assessed by the FLI. These results suggest that diet, especially the Mediterranean model, it is an important factor in the pathogenesis and development of NAFLD. The results indicate that the composition of the diet may influences the severity and progression of the disease by increasing the inflammation and oxidative stress. On the other hand, in our study, nut consumption appears to be the best predictor for FLI. ${ }^{143}$

Several studies have investigated the correlation between nuts consumption and cardiovascular diseases. ${ }^{144}$ However few 
investigations have investigated the correlations between consumption of nuts and NAFLD. ${ }^{144}$ In terms of energy and nutrients, $30 \mathrm{~g}$ of dried nuts provide $206.6 \mathrm{Kcal}$, distributed as $4.3 \mathrm{~g}$ of protein, $20.4 \mathrm{~g}$ of fat, $1.5 \mathrm{~g}$ of carbohydrate, and $1.9 \mathrm{~g}$ of fibers. ${ }^{145}$ Due to their content of $\alpha$-tocopherol and selenium, as well as vitamins of the B group, such as B1 and B6 and minerals such as copper, zinc, phosphorus and magnesium, nuts are considered an important source of antioxidants. ${ }^{146}$ The anti-oxidant effects of nuts, appears to be the consequence of a particular composition in polyunsaturated fatty acids, such as linoleic acid $(30.02 \%), \alpha$-linolenic acid $(6.64 \%)$ and monounsaturated, such as oleic acid (9.38\%), as well as from the content in plant sterols, polyphenols, minerals (particularly magnesium and potassium). ${ }^{147-149}$ Furthermore, Tapsell et al. have shown that the intake of 30 grams of nuts /day (about 5-6 nuts) leads to an improvement of the lipid profile. ${ }^{150}$

In a subgroup of 50 patients with moderate to severe obesity underwent hospitalization due to thyroid dysfunction it was observed that, in obese subjects TSH levels were positively correlated with BMI and waist circumference. Furthermore, these results were also confirmed by bioelectrical impedance analysis, which showed a positive correlation between TSH and FM. Finally positive correlations were also reported between TSH, blood glucose, insulin and HOMA-IR index. From a strictly dietary and nutritional point of view, the results of this study also showed that the deiodination index, expressed by the $\mathrm{fT}_{3} / \mathrm{fT}_{4}$ ratio, was positively correlated with the percentage of $\mathrm{CHO}$ and negatively correlated with the percentage of fat present in the diet but not with the total caloric value. $\mathrm{CHO}$ content was proven to be the best predictor of $\mathrm{fT}_{3} / \mathrm{fT}_{4}$ ratio by linear regression analysis. The positive association between TSH, BMI and waist circumference is commonly reported among obese subjects. ${ }^{74,75}$ The correlation between TSH and BMI may be mediated by leptin, an important regulator of neuroendocrine HPT axis. ${ }^{80}$ This effect may be considered as the consequence of the positive influence of TSH on adipogenesis which results in an increased release of insulin to compensate for IR. ${ }^{80}$ Other studies analyzed the onset of resistance to insulin receptors that may be associated with a resistance of thyroid receptors. ${ }^{83}$ However it is unclear whether the positive correlation between IR and TSH levels should be interpreted as a consequence of metabolic resistance of receptors for thyroid hormones or as the positive effect of the influence of TSH on adipogenesis as a consequence of the increased release of insulin to counteract IR. Although it is known that the deiodination is strongly influenced by nutritional metabolic factors, few experimental observations, (none of which obtained from human studies), have documented a possible influence of qualitative and quantitative differences of nutrients intake on the relationship between thyroid function and obesity. ${ }^{151,152}$ Numerous studies have demonstrated that $\mathrm{CHO}$ are able to modulate the peripheral metabolism of thyroid hormones by deiodination of $T_{4}$ to $T_{3}$ in the liver via the enzyme 5 'deiodinase type $1 .{ }^{93,94} \mathrm{In}$ humans, $\mathrm{T}_{3}$ serum levels are directly associated with rate of $\mathrm{CHO}$ intake. ${ }^{153}$ In particular, during caloric restriction diet, especially diets low in $\mathrm{CHO}$, the reduction of the production peripheral $\mathrm{T}_{3}$ induces a decrease reduction of $\mathrm{fT}_{3}$ blood levels. ${ }^{150}$ Several studies have also revealed that in humans, the production of $\mathrm{T}_{3}$ from $\mathrm{T}_{4}$ decreases during fasting and is restored following refeeding. ${ }^{94,96}$ In particular, the re-feeding, with $\mathrm{CHO}$, is able to reverse the changes in serum $\mathrm{T}_{4}, \mathrm{~T}_{3}, \mathrm{rT}_{3}$ and $\mathrm{TSH}$ caused by fasting. ${ }^{97}$ Instead, meals rich in $\mathrm{CHO}$ induce a significant increase in the 5'-deiodinase activity both in brown adipose tissue and the liver which are not associated with significant changes in serum levels of thyroid hormones. ${ }^{153,154}$ However, in the case of highcalorie diet, especially diet rich in carboydrates, $\mathrm{T}_{3}$ levels increase, those of $\mathrm{rT}_{3}$ decrease, while the levels of the $\mathrm{T}_{4}$ do not undergo substantial changes. ${ }^{155}$ Regarding lipids, previous studies have shown their effects on thyroid function. ${ }^{102}$ In particular, in vivo experiments showed that the increase in the content of oxidized lipids resulted in an increase in circulating levels of $\mathrm{T}_{4}$. This effects may be probably due to a reduction of the circulating levels of selenium and a consequent reduction in the activity of the type I 5 'desiodase. ${ }^{104}$

\section{Conclusions}

The complications regarding the neuroendocrine axes arising in overweight patients as a consequence of obesity, are not well known. Although secondary, the dysregulation of the endocrine system, may act by amplifying the metabolic alterations and body composition. These changes contribute to the variability of phenotypic expression in obese subjects and worsen the cardio-metabolic and cancer risk. ${ }^{156,157}$ Increasing evidence highlights a close relationship between nutrition and endocrine system. Data from other studies are in agreement with the reduction of GH secretion in obese subject and the secretory deficit of the GH/IGF-1 which take place in a functional manner following the increase of visceral fat. These effects may, in turn, contribute to determine a further accumulation of visceral fat thus increasing the risk of cardiovascular and metabolic diseases. As far as it concerns thyroid hormones, the peripheral deiodination, assessed by the $\mathrm{fT}_{3} / \mathrm{fT}_{4}$ ratio, is positively influenced by $\mathrm{CHO}$ content and negatively by the lipid content of the diet, but not by the total caloric value. ${ }^{94}$ The effects of nutrients on thyroid hormone metabolism suggest that it is necessary to take into account the nutritional asset of patients. Therefore, the nutritional analysis associated with thyroid function may be important and may help to find the appropriate therapeutic approach which may be helpful to personalize dietary regimes. In fact foods, may exerts powerful, immediate and long term effects on the production of circulating hormones and, at the same time, many physiological actions of the foods take place by hormonal intervention. Therefore, the results underline the importance of an appropriate evaluation of body composition and nutritional profile, not only in terms of caloric intake, but also in terms of nutrients distribution as an essential prerequisite in the assessment of endocrine axes in obese subjects.

\section{References}

1. Bastien M, Poirier P, Lwmieux I, Després JP. Overview of epidemiology and contribution of obesity to cardiovascular disease. Prog Cardiovasc Dis 2014;56:369-81.

2. Bray GA, Kim KK, Wilding JPH. World Obesity Federation. Obesity: a chronic relapsing progressive disease process. A position statement of the World Obesity Federation. Obes Rev 2017; 18:715-23.

3. Poddar M, Chetty Y, Chetty VT. How does obesity affect the endocrine system? A narrative review. Clin Obes 2017;7:136-44.

4. Panagiotis Kokkoris P, Pi-Sunyer X. Obesity and endocrine disease. Endocrinol Metab Clin N Am 2003;32:895-914.

5. Pedersen SD. Metabolic complications of obesity. Best Pract Res Clin Endocrinol Metab 2013;27:179-93.

6. Wildman RP, Muntner P, Reynolds K, et al. The obese without cardiometabolic risk factor clustering and the normal weight 
with cardiometabolic risk factor clustering: prevalence and correlates of 2 phenotypes among the US population (NHANES 1999- 2004). Arch Intern Med 2008;168:1617-24.

7. Pasquali R, Vicennati V, Gambineri A, Pagotto U. Hormones and pathophysiology of obesity. Eat Weight Disord 2001;6:9-20.

8. Savastano S, Di Somma C, Mentone A. et al. GH insufficiency in obese patients. J Endocrinol Invest 2006;29:42-53.

9. Maccario M. Grottoli S, Procopio M, et al. The GH/IGF-I axis in obesity: influences of neuroendocrine and metabolic factors. Int J Obes Relat Disord 2000;24:S96-9.

10. Møller N, Gjedsted J, Gormsen L, et al. Effects of growth hormone on lipid metabolism in humans. Growth Horm IGF Res 2003;13:S18-21.

11. Scacchi M, Pincelli AI, Cavagnini F, et al. Growth hormone in obesity. Int J Obes Relat Metab Disord 1999;23:260-71.

12. Godenberg N, Barkan A. Factors regulating growth hormone secretion in humans. Endocrinol Metab Clin N Am 2007;36:37-55.

13. Broglio F, Benso A, Gottero C, et al. Effects of glucose, free fatty acids or arginine load on the GH-releasing activity of ghrelin in humans. Clin Endocrinol 2002;57:265-71.

14. Mazziotti G, Giustina A. Glucocorticoids and the regulation of growth hormone secretion. Nat Rev Endocrinol 2013;9:265-76.

15. Laron $Z$. Interactions between the thyroid hormones and the hormones of the growth hormone axis. Pediatr Endocrinol Rev 2003;12:244-50.

16. Paulo RC. Gonadal status and body mass index jointly determine growth hormone (GH)-releasing hormone/GH-releasing peptide synergy in healthy men. J Clin Endocrinol Metab 2008;93:944-50.

17. Pombo M, Maccario M, Seoane LM, et al. Control and function of the GH-IGF-1 axis in obesity. Eat Weight Disord 2001;6:22-7.

18. Oscarsson J, Ottosson M, Eden S. Effects of growth hormone on lipoprotein lipase and hepatic lipase. J Endocrinol Invest 1999;22:2-9

19. Oscarsson J, Ottosson M, Johansson JO, et al. Two weeks of daily injections and continuous infusion of recombinant human growth hormone (Gh) in Gh-deficient adults. Ii. Effects on Serum Lipoproteins and Lipoprotein and Hepatic Lipase Activity. Metabolism 1996;45:370-7.

20. Jørgensen JO, Rubeck KZ, Nielsen TS, et al. Effects of GH in human muscle and fat. Pediatr Nephrol 2010;25:705-9.

21. Phillips LS, Unterman TG. Somatomedin activity in disorders of nutrition and metabolism. Clin Endocrinol Metab 1984;13:145-89.

22. Moller N, Vendelbo MH, Kampmann U, et al. Growth hormone and protein metabolism. Clin Nutr 2009;28:597-603.

23. Beauregard C, Utz AL, Schaub AE, et al. Growth hormone decreases visceral fat and improves cardiovascular risk markers in women with hypopituitarism: a randomized, placebocontrolled study. J Clin Endocrinol Metab 2008;93:2063-71.

24. Richelsen B. Effect of growth hormone on adipose tissue and skeletal muscle lipoprotein lipase activity in humans. J Endocrinol Invest 1999;22:10-5.

25. Vijayakumar A, Novosyadlyy R, Wu Y, et al. Biological effects of growth hormone on carbohydrate and lipid metabolism. Growth Horm IGF Res 2010;20:1-7.

26. Mauras N, O'Brien K, Welch S. et al. Insulin-like growth factor $\mathrm{i}$ and growth hormone (Gh) treatment in Gh-deficient humans: differential effects on protein, glucose, lipid, and Calcium Metabolism. J Clin Endocrinol Metab 2000;85:1686-94.
27. Norrelund H, Riis AL, Moller N. Effects of GH on protein metabolism during dietary restriction in man. Growth Horm IGF Res 2002; 12:198-207.

28. Goldenberg N, Barkan A. Factors regulating growth hormone secretion in humans. Endocrinol Metab Clin North Am 2007;36:37-55.

29. van Vught AJ, Nieuwenhuizen AG, Brummer RJM, Westerterp-Plantenga MS. Effects of oral ingestion of amino acids and proteins on the somatotropic axis. J Clin Endocrinol Metab 2008;93:584-90.

30. Thissen JP, Ketelslegers JM, Underwood LE. Nutritional regulation of insulin-like growth factors. Endocr Rev 1994;15:80-101.

31. Yamamoto M, Iguchi G, Fukuoka H, et al. SIRT1 regulates adaptive response of the growth hormone-insulin-like growth factor-I axis underfasting conditions in liver. Proc Natl Acad Sci USA 2013;110:14948-53.

32. Livingstone C. Insulin-like growth factor-I (IGF-I) and clinical nutrition. Clin Sci 2013;125:265-80.

33. Michaelsen KF. Effect of protein intake from 6 to 24 months on insulin-like growth factor 1 (IGF-1) levels, body composition, linear growth velocity, and linear growth acceleration: what are the implications for stunting and wasting? Food Nutr Bull 2013;34:268-71.

34. Larnkjær A. Amberg K, Michaelsen KF, et al. Effect of milk proteins on linear growth and IGF variables in overweight adolescents. Growth Horm IGF Res 2014; 24:54-9.

35. Norat T, Dossus L, Rinaldi S, et al. Diet, serum insulin-like growth factor-I and IGF-binding protein-3 in European women. Eur J Clin Nutr 2007;61:91-8.

36. Kaklamani VG, Linos A, Kaklamani E, et al. Dietary fat and carbohydrates are independently associated with circulating insulin like growth factor 1 and insulin-like growth factorbinding protein 3 concentrations inhealthy adults. J Clin Oncol 1999; 17:3291-8.

37. De Boer H. Blok GJ, Van Der Veen EA, et al. Clinical aspects of growth hormone deficiency in adults. Endocr Rev 1995; 16:63-86.

38. Newmann CB, Kleinberg DL. Adult growth hormone deficiency. The Endocrinologist 1998;8:178-86.

39. Vance ML, Mauras N. Growth hormone therapy in adults and children. N Engl J Med 1999;16:1206-16.

40. Carrol PV, Christ ER. Growth hormone deficiency in adulthood and the effects of growth hormone replacement: a review. J Clin Endocrinol Metab 1998;83:382-95.

41. Molitch ME, Clemmons DR, Malazowski S, et al. Evaluation and treatment of adult growth hormone deficiency: an endocrine society clinical practice guideline. J Clin Endocrinol Metab 2011;96:1587-609.

42. Hartman ML, Crove BJ, Biller BMK, et al. HypoCCS Study Group Which patient do not require a GH stimulation test for the diagnosis of adult GH deficiency? J Clin Endocrinol Metab 2002;87:477-85.

43. Aimaretti G, Corneli G, Razzone P, et al. Comparison between insulin-induced hypoglycemia and growth hormone (GH)-releasing hormone+arginine as provocative tests for the diagnosis of GH deficiency in adults. J Clin Endocrinol Metab 1998;83:1615-8.

44. Ghigo E. Diagnosis of adult GH deficiency. Growth Horm IGF Res 2008;18:1-16.

45. Corneli G, Di Somma C, Bardelli R, et al. The cut-off limits of the $\mathrm{GH}$ response to GH-releasing hormone-arginine test related to body mass index. Eur J Endocrinol 2005;153:257-64. 
46. Ghigo E, Aimaretti G, Arvat E, et al. Growth hormone-releasing hormone combined with arginine or growth hormone secretagogues for the diagnosis of growth hormone deficiency in adults. Endocrine 2001;15:29-38.

47. Cordido F, Alvarez Castro P, Isidro ML, et al. Comparison between insulin tolerance test, growth hormone $(\mathrm{GH})$-releasing hormone (GHRH), GHRH plus acipimox and GHRH plus GH- releasing peptide- 6 for the diagnosis of adult GH deficiency in normal subjects, obese and hypopituitary patients. Eur J Endocrinol 2003;149:117-22.

48. Di Somma C, Savastano S, Rota F, et al. Appropriate use of stimulation tests and insulin-like growth factor-I in obesity. J Endocrinol Invest 2008;31:21-6.

49. Growth Hormone Research Society (GRS). Consensus guidelines for the diagnosis and treatment of adults with Growth hormone deficiency: summary statement of the Growth Hormone Research Society Workshop on adult growth hormone deficiency. J Clin Endocrinol Metab 1998;83:379-81.

50. Johansson AG, Engstrom BE, Ljunghall S, et al. Gender differences in the effects of long term growth hormone $(\mathrm{GH})$ treatment on bone in adults with GH deficiency. J Clin Endocrinol Metab 1999;84:2002-7.

51. Nilsson AG, Svensson J, Johannsson G. Management of growth hormone deficiency in adults. Growth Horm IGF Res 2007; 17:441-62.

52. Attanasio AF, Lamberts SWJ, Matranga AMC, et al. Adult growth hormone (GH)-deficient patients demonstrate heterogeneity between childhood onset and adult onset before and during human GH treatment. Adult Growth Hormone Deficiency Study Group. J Clin Endocrinol Metab 1997;82:82-8.

53. Colao A, Cerbone G, Pivonello R. et al. The growth hormone $(\mathrm{GH})$ response to the arginine plus $\mathrm{GH}$ - releasing hormone test is correlated to the severity of lipid profile abnormalities in adult patients with GH deficiency. J Clin Endocrinol Metab 1999;84:1277-82.

54. Bengtsson BA, Edén S, Lönn L. et al. Treatment of adults with growth hormone $(\mathrm{GH})$ deficiency with recombinant human GH. J Clin Endocrinol Metab 1993;76:309-17.

55. Hoffman AR, Kuntze JE, Baptista J, et al. Growth hormone $(\mathrm{GH})$ replacement therapy in adult-onset GH deficiency: effects on body composition in men and women in a doubleblind, randomized, placebo-controlled trial. J Clin Endocrinol Metab 2004;89:2048-56.

56. Chrisoulidou A, Beshyah SA, Rutherford O, et al. Effects of 7 years of growth hormone replacement. J Clin Endocrinol Metab 2000;85:3762-9.

57. Johannsson G, Grimby G, Sunnerhagen KS, Bengtsson BA. Two years of growth hormone $(\mathrm{GH})$ treatment increase isometric and isokinetic muscle strength in GH-deficient adults. J Clin Endocrinol Metab 1997;82:2877-84.

58. Götherström G, Elbornsson M, Stibrant-Sunnerhagen K, et al. Ten years of growyh hormone replacement normalizes muscle strength in GH-deficient adults. J Clin Endocrinol Metab 2009;943:809-16.

59. Yang S, Cao L, Cai S, et al. A systematic review of growth hormone for hip fractures. Growth Horm IGF Res 2012;22:97-101.

60. Colao A, Di Somma C, Pivonello R, et al. Bone loss is correlated to the severity of growth hormone $(\mathrm{GH})$ deficiency in adult patients with hypopituitarism. J Clin Endocrinol Metab 1999;84:1919-24.

61. Saggese G, Baroncelli GI, Bertelloni S, Barsanti S. The effect of long term growth hormone $(\mathrm{GH})$ treatment on bone mineral density in children with GH deficiency. Role of GH in the attainance of peak bone mass. J Clin Endocrinol Metab 1996;81:3077-83.

62. Colao A, di Somma C, Pivonello R, et al. The cardiovascular risk of adult $\mathrm{GH}$ deficiency (GHD) improved after $\mathrm{GH}$ replacement and worsened in untreated GHD: a 12-month prospective study. J Clin Endocrinol Metab 2002;87:1088-93.

63. Colao A, Di Somma C, Spiezia, et al. Growth hormone treatment on atherosclerosis: results of a 5-year open, prospective, controlled study in male patients with severe growth hormone deficiency. J Clin Endocrinol Metab 2008;93:3416-24.

64. Costa-e-Sousa RH, Hollenberg AN. The neural regulation of the hypothalamic-pituitary-thyroid axis. Endocrinology 2012;153:4128-35.

65. Chiamolera MI, Wondisford FE. Thyrotropin-releasing hormone and the thyroid hormone feedback mechanism. Endocrinology 2009; 150:1091-6.

66. Scanlan TS1, Suchland KL, Hart ME, et al. 3Iodothyronamine is an endogenous and rapid-acting derivative of thyroid hormone. Nat Med 2004;10:638-42.

67. Inada M, Nishikawa M. Thyroid hormone metabolism. Nihon Naibunpi Gakkai Zasshi 1993;69:9-15.

68. Chidakel A, Mentuccia D, Celi FS. Peripheral metabolism of thyroid hormone and glucose homeostasis. Thyroid 2005;8:899-903.

69. Debaveye Y, Ellger B, Mebis L, et al. Regulation of tissue iodothyronine deiodinase activity in a model of prolonged critical illness, Thyroid 2008;18:551-60.

70. Pujanek M, Bronisz A, Małecki P, Junik R. Pathomechanisms of the development of obesity in some endocrinopathies - an overview. Endokrynol Pol 2013;64:150-5.

71. Ghamari-Langroudi M, Vella KR, Srisai D, et al. Regulation of thyrotropin-releasing hormone- expressing neurons in paraventricular nucleus of the hypothalamus by signals of adiposity. Mol Endocrinol 2010;24:2366-81.

72. Rotondi M, Leporati P, La Manna A, et al. Raised serum TSH levels in patients with morbid obesity: is it enough to diagnose subclinical hypothyroidism? Eur J Endocrinol 2009;160:403-8.

73. Kok P, Roelfsema F, Langendonk JG et al. High circulating thyrotropin levels in obese women are reduced after body weight loss induced by caloric restriction. J Clin Endocrinol Metab 2005;90:4659-63.

74. Reinehr T, Isa A, de Sousa G, et al. Thyroid hormones and their relationship to weight status. Horm Res 2008;70:51-7.

75. Mehran L, Amouzegar A, Delshad H, Azizi F. Association between serum TSH concentration and body mass index in euthyroid subjects: the role of smoking. Arch Iran Med 2012;15:400-3.

76. Knudsen N. Laurberg P, Rasmussen LB, et al. Small differences in thyroid function may be important for body mass index and the occurrence of obesity in the population. J Clin Endocrinol Metab 2005;90:4019-24.

77. Svare A, Nilsen TI, Bjoro T, et al. Serum TSH related to measures of body mass: longitudinal data from the HUNT Study, Norway. Clin Endocrinol 2011;74:769-75.

78. Reinehr T. Obesity and thyroid function. Mol Cell Endocrinol 2010;316:165-71.

79. Michalaki M, Vagenakis AG, Argentou M, et al. Dissociation of thyrotropin and leptin secretion in acute surgical stress in severely obese patients. Obes Surg 2009;19:1424-9.

80. Mantzoros CS, Ozata M, Negrao AB, et al. Synchronicity of 
frequently sampled thyrotropin (TSH) and leptin concentrations in healthy adults and leptin-deficient subjects: evidence for possible partial TSH regulation by leptin in humans. J Clin Endocrinol Metab 2001;86:3284-91.

81. Gertig AM, Niechcial E, Skowronska B. Thyroid axis alterations in childhood obesity. Pediatr Endocrinol Diabetes Metab 2012;18:116-9.

82. Ren R, Jiang X, Zhang X, et al. Association between thyroid hormones and body fat in euthyroid subjects. Clin Endocrinol. 2014;80:585-90.

83. Ambrosi B, Masserini B, Iorio L, et al. Relationship of thyroid function with body mass index and insulin-resistance in euthyroid obese subjects. J Endocrinol Invest 2010;33:640-3.

84. Kok P, Roelfsema F, Langendonk JG, et al. High circulating thyrotropin levels in obese women are reduced after body weight loss induced by caloric restriction. J Clin Endocrinol Metab 2005;90:4659-63.

85. Croxson MS, Hall TD, Kletzky OA, et al. Decreased serum thyrotropin induced by fasting. J Clin Endocrinol Metab 1977;45:560-8.

86. Lips MA, Pijl H, van Klinken JB, et al. Roux-en-Y gastric bypass and calorie restriction induce comparable time dependent effects onthyroid hormone function tests in obese female subjects. Eur J Endocrinol 2013;169:339-47.

87. Khan SM, Hamnvik OP, Brinkoetter M, Mantzoros CS. Leptin as a modulator of neuroendocrine function in humans. Yonsei Med J 2012 1;53:671-9.

88. Jonas W, Lietzow J, Wohlgemuth F. 3,5-Diiodo-L-thyronine $(3,5-\mathrm{t} 2)$ exerts thyromimetic effects on hypothalamus-pituitary thyroid axis, body composition, and energy metabolism in male diet induced obese mice. Endocrinology 2015;156:389-99.

89. Giammanco M, Aiello S, Casuccio A, et al. Effects of 3,5diiodo-L-thyronine on the liver of high fat diet fed rats. Journal of Biological Research 2016;89:4-9.

90. Biondi B. Thyroid and obesity: an intriguing relationship. J Endocrinol Metabol 2010;95:3414-617.

91. Tóth G, Noszál B. Thyroid hormones and their precursors I. Biochemical properties. Acta Pharm Hung 2013;832:35-45.

92. Oppenheimer JH. Thyroid today. Flint Laboratories; 1980.

93. Leonard JL, Visser TJ. Biochemistry of Deiodination. In: Hennemann G, ed. Thyroid hormone metabolism. New York, NY: Marcel Dekker; 1986; pp 189-229.

94. Spauling SW, Chopra IJ, Sherwin RS, Lyall SS. Effect of caloric restriction and dietary composition on serum T3 and rT3 in man. J Clin Endocrinol Metab 1976;42:197.

95. Glick Z, Wu SY, Lupien J, et al. Meal-induced brown fat thermogenesis and thyroid hormone metabolism in rats. Am J Physiol 1985;249:519-24.

96. Vagenakis A G, Portanay GI, O Brian JT, et al. Effect of starvation on the production and metabolism of thyroxine and triiodothyronine in euthyroid obese patients. J Clin Endocrinol Metab 1977;45,1305-9.

97. Harris AR, Fang SL, Azizi F, et al. Effect of starvation on hypothalamic-pituitary-thyroid function in the rat. Metabolism 1978;27:935-42.

98. Choi JW, Choi HS. The regulatory effects of thyroid hormone on the activity of 3-hydroxy-3-methylglutaryl coenzyme A reductase. Endocr Res 2000;26:1-21.

99. Asvold BO, Vatten LJ, Nilsen TI, Bjøro T. The association between TSH within the reference range and serum lipid concentrations in a population-based study. The HUNT Study. Eur J Endocrinol 2007;156:181-6.
100. Wang F, Tan Y, Wang C, et al. Thyroid-stimulating hormone levels within the reference range are associated with serum lipid profiles independent of thyroid hormones. J Clin Endocrinol Metab 2012;97:2724-31.

101. Asvold BO, Vatten LJ, Nilsen TI, Bjøro T. The association between TSH within the reference range and serum lipid concentrations in a population- based study. Eur J Endocrinol 2007;156:181-6.

102. Eder K, Skufca P, Brandsch C. Dietary fats increase plasma thyroxine concentrations in rats irrespective of the vitamin e and selenium supply. J Nutr 2002;132:1275-81.

103. Burki TK. TSH, blood pressure, and lipid levels. Lancet Diabetes Endocrinol 2013;1:s12.

104. Araujo RL, Andrade BM, Padrón AS, et al. High-fat diet increases thyrotropin and oxygen consumption without altering circulating 3,5,3'-triiodothyronine (T3) and thyroxine in rats: the role of iodothyronine deiodinases, reverse T3 production, and whole-body fat oxidation. Endocrinology 2010;151:3460-9.

105. Hoffman R, Gerber M. Evaluating and adapting the Mediterranean diet for non-Mediterranean populations: a critical appraisal. Nutr Rev 2013;71:573-84.

106. Castro-Quezada I, Román-Viñas B, Serra-Majem L. The Mediterranean diet and nutritional adequacy: a review. Nutrients 2014;6:231-48.

107. Esposito K, Kastorini CM, Panagiotakos DB, Giugliano D. Mediterranean diet and metabolic syndrome: an updated systematic review. Rev Endocr Metab Disord 2013;14:255-63.

108. Sofi F, Cesari F, Abbate R, et al. Adherence to Mediterranean diet and health status: meta-analysis. BMJ 2008;337:a13144.

109. Baldini M, Pasqui F, Bordoni A, Maranesi M. Is the Mediterranean lifestyle still a reality? Evaluation of food consumption and energy expenditure in Italian and Spanish university students. Public Health Nutr 2009;12:148-55.

110. Sáez-Almendros S, Obrador B, Bach-Faig A, Serra-Majem L. Environmental footprints of Mediterranean versus Western dietary patterns: beyond the health benefits of the Mediterranean diet. Environ Health 2013 30;12:118.

111. Vasto S, Barera A, Rizzo C, et al. Mediterranean Diet And Longevity: An Example Of Nutraceuticals? Curr Vasc Pharmacol 2014;12:735-8.

112. Sofi F, Macchi C, Abbate R, et al. Mediterranean diet and health status: an updated meta- analysis and a proposal for a literature-based adherence score. Public Health Nutr 2013;29:1-14

113. Funtikova AN, Benítez-Arciniega AA, Gomez SF, et al. Mediterranean diet impact on changes in abdominal fat and 10-year incidence of abdominal obesity in a Spanish population. Br J Nutr 2014;111:1481-7.

114. Bonaccio M, Di Castelnuovo A, Costanzo S, et al. Nutrition knowledge is associated with higher adherence to Mediterranean diet and lower prevalence of obesity. Results from the Moli-sani study. Appetite 2013;68:139-46.

115. Schröder H. Protective mechanisms of the Mediterranean diet in obesity and type 2 diabetes. J Nutr Biochem 2007;18:149-60.

116. Nadtochiy SM, Redman EK. Mediterranean diet and cardioprotection: the role of nitrite, polyunsaturated fatty acids, and polyphenols. Nutrition 2011;27:733-44.

117. Schröder H1, Marrugat J, Vila J, et al. Adherence to the traditional mediterranean diet is inversely associated with body mass index and obesity in a spanish population. J Nutr 2004; 134:3355-61.

118. Chilliard Y, Ferlay A, Rouel J, Lamberet G. A review of nutri- 
tional and physiological factors affecting goat milk lipid synthesis and lipolysis. JDS 2003;86:1751-70.

119. Boelsma E, Kloek J. IPP-rich milk protein hydrolysate lowers blood pressure in subjects with stage 1 hypertension, a randomized controlled trial. Nutr J 2010;8:52.

120. Satija A, Agrawal S, Bowen L, et al. Association between milk and milk product consumption and anthropometric measures in adult men and women in India: a cross- sectional study. PLoS One 2013 8;8:e60739.

121. Kwon HT, Lee CM, Park JH, et al. Milk intake and its association with metabolic syndrome in Korean: analysis of the third Korea National Health and Nutrition Examination Survey (KNHANES III). J Korean Med Sci 2010;25:1473-9.

122. McCarron DA, Morris CD, Henry HJ, Stanton JL. Blood pressure and nutrient intake in the United States. Science 1984;224:1392-8.

123. Zemel MB, Shi H, Greer B, et al. Regulation of adiposity by dietary calcium. FASEB J 2000;14:1132-8.

124. Newby PK, Muller D, Hallfrisch J, et al. Dietary patterns and changes in body mass index and waist circumference in adults. Am J Clin Nutr 2003;77:1417-25.

125. Rosell M, Håkansson NN, Wolk A. Association between dairy food consumption and weight change over $9 \mathrm{y}$ in 19,352 perimenopausal women. Am J Clin Nutr 2006;84:1481-8.

126. Barba G, Troiano E, Russo $\mathrm{P}$, et al. Inverse association between body mass and frequency of milk consumption in children. Br J Nutr 2005;93:15-9.

127. Marques-Vidal P, Gonçalves A, Dias CM. Milk intake is inversely related to obesity in men and in young women: data from the Portuguese Health Interview Survey 1998-1999. Int J Obes 2006;30:88-93.

128. Gilbert JA, Joanisse DR, Chaput JP, et al. Milk supplementation facilitates appetite control in obese women during weight loss: a randomised, single-blind, placebo-controlled trial. Br J Nutr 2011;105:133-43.

129. Zemel MB. Proposed role of calcium and dairy food components in weight management and metabolic health. Phys Sportsmed 2009;37:29-39.

130. Zemel MB. Regulation of adiposity and obesity risk by dietary calcium: mechanisms and implications. JCN 2002;21:146S-51.

131. Zemel MB, Miller SL. Dietary calcium and dairy modulation of adiposity and obesity risk. Nutr Rev 2004;62:125-31.

132. Diersen-Schade DA, Richard MJ, Jacobson NL. Effects of dietary calcium and fat on cholesterol in tissues and feces of young goats. J Nutr 1984;114:2292-300.

133. Jacobsen R, Lorenzen JK, Toubro S, et al. Effect of shortterm high dietary calcium intake on 24-h energy expenditure, fat oxidation, and fecal fat excretion. Int J Obes 2005;29:292-300.

134. Bendsen NT, Hother AL, Jensen SK, et al. Effect of dairy calcium on fecal fat excretion: a randomized crossover trial. Int J Obes 2008;32:1816-24.

135. Bush NC1, Alvarez JA, Choquette SS, et al. Dietary Calcium intake is associated with less gain in intra abdominal adipose tissue over 1 year. Obesity 2010;18:2101-4.

136. Shi H, Dirienzo D, Zemel MB. Effects of dietary calsium on adipocyte lipid metabolism and body weight regulation in energy-restricted ap2-agouti transgenic mice. FASEB J 2000;8:291-330.

137. Cantó C, Houtkooper RH, Pirinen E, et al. The NAD $(+)$ precursor nicotinamide riboside enhances oxidative metabolism and protects against high-fat diet-induced obesity. Cell Metab 2012;15:838-47.

138. Major GC, Chaput JP, Ledoux M, et al. Recent developments in calcium-related obesity research. Obes Rev 2008;9:428-45.

139. Savastano S, Di Somma C, Belfiore A, et al. Growth hormone status in morbidly obese subjects and correlation with body composition. JEI 2006;29:536-43.

140. Akanji AO, Smith RJ. The insulin-like growth factor system, metabolic syndrome, and cardiovascular disease risk. Metab Syndr Relat Disord 2012;10:3-13.

141. Lohr J, Grotevendt A, Nauck M, et al. Relation of insulin-like growth factor-I and IGF binding protein 3 with markers of inflammation: results of a population-based study. Clin Endocrinol 2014;80:148-54

142. Makimura $\mathrm{H}$. The effects of central adiposity on growth hormone $(\mathrm{GH})$ response to GH-releasing hormone-arginine stimulation testing in men. J Clin Endocrinol Metab 2008;93:4254-60.

143. Ryan MC, Desmond P, Wilson A. Reply to: "might some of the beneficial effects of the Mediterranean diet on non-alcoholic fatty liver disease be mediated by reduced iron stores?". J Hepatol 2013;59:640.

144. Dreher ML. Pistachio nuts: composition and potential health benefits. Nutr Rev 2012;70:234-40.

145. National Institute of Research for Food and Nutrition (INRAN). Food composition tables: dry walnuts.

146. European Food Safety Autority (EFSA). Regulations (UE) n. 432/2012.

147. Maguire LS, O'Sullivan SM, Galvin K, et al. Fatty acid profile, tocopherol, squalene and phytosterol content of walnuts, almonds, peanuts, hazelnuts and the macadamia nut. Int $\mathrm{J}$ Food Sci Nutr 2004;55:171-8.

148. Strahan TM. Nuts for cardiovascular protection. Asia Pac J Clin Nutr 2004; 13:S33.

149. Kris-Etherton PM, Yu-Poth S, Sabaté J,et al. Nuts and their bioactive constituents: effects on serum lipids and other factors that affect disease risk. Am J Clin Nutr. 1999;70:504-11.

150. Tapsell LC, Gillen LJ, Patch CS, et al. Including walnuts in a low-fat/modified-fat diet improves HDL cholesterol-to-total cholesterol ratios in patients with type 2 diabetes. Diabet Care 2004;27:2777-83.

151. Gavin LA, Bui F, Mc-Mahon F, Cavallieri RR. Sequential deiodination of thyroxine to 3-3 tiiodothyonine via 3,5,3 triiodothyronine and $3,3,5$ triiodothyronine in rat liver homogenate:the effects of fasting versus glucose feeding. J Biol Chem 1980;254:49-54.

152. Danforth E, Horton ES, O'Connell M, et al. Dietary-induced Alterations in Thyroid Hormone Metabolism during Overnutrition. J Clin Invest. Am Society Clin Invest 1979;64:1336-47.

153. Geoffrey J. Eales The influence of nutritional state on thyroid function in various vertebrates. Oxford J Life Sci Integr Compar Biol 2011;20:351-62.

154. Suda AK, Pittman CS, Shimizu T, Chambers JB. The production and metabolism of 3,5,3'- triiodothyronine and 3,3',5-triiodothyronine in normal and fasting subjects. J Clin Endocrinol Metab 1978;7:1311-31.

155. Schwartz HL, Lancer SR, Oppenheimer JH. Thyroid hormones influence starvation-induced hepatic protein loss in the rat: possible role of thyroid hormones in the generation of labile. Endocrinology 2013;107:1684-92.

156. Tabacchi G, Giammanco S, La Guardia M, Giammanco M. A review of the literature and a new classification of the early determinants of childhood obesity: from pregnancy to the first years of life. Nutrition Research 2007;27:587-604.

157. La Guardia M, Giammanco M, Breast cancer and obesity. Panminerva Medica 2001;42:123-33. 